\title{
The cytoskeleton of human myometrial cells
}

\author{
J. T. H. T. Yu and A. López Bernal* \\ Nuffield Department of Obstetrics and Gynaecology, University of Oxford, John Radcliffe Hospital, \\ Headington, Oxford OX3 9DU, UK
}

\begin{abstract}
Eukaryotic cells have an internal cytoskeletal scaffolding, giving them their distinctive shapes. The cytoskeleton enables cells to transport vesicles, undergo changes in shape, migrate and contract. This dynamic structure is formed by three classes of filamentous assembly: actin microfilaments, intermediate filaments and microtubules. In this investigation the cytoskeleton of cultured human myometrial cells was studied by immunohistochemistry using specific antibodies against vinculin, cytokeratin, vimentin, tubulin and RhoA, covalently labelled with a fluorescent tag. Polymerized actin was visualized with fluoresceinconjugated phalloidin. Myometrial cells were very rich in actin fibres, which generally appeared as parallel bundles along the longest axis of the cells. There was a strong expression of vinculin which concentrated at actin-vinculin focal adhesion sites. By contrast, intermediate filaments (vimentin and cytokeratin) were organized in a dense cytoplasmic meshwork which excluded the nuclear space. A similar pattern was observed for tubulin. RhoA had a diffuse distribution and was associated with actin fibres. Exposure of the cells to oxytocin provoked a $10 \%$ shortening of actin stress fibres. These results demonstrate that myometrial smooth muscle cells have a rich cytoskeletal structure and that agonists that stimulate myometrial activation provoke measurable changes in actin fibres which may be important for efficient contractility.
\end{abstract}

\section{Introduction}

The cytoskeleton is a dynamic structure that allows eukaryotic cells to adapt to a variety of shapes and to carry out co-ordinated and directed movements. Moreover, transport of vesicles inside the cell requires the interaction of cytoskeletal proteins and intracellular signalling systems such as Rho (Murphy et al., 1996). Rho belongs to the family of small GTP-binding proteins (Hall, 1994) that have been implicated in the signalling processes that activate actin fibres during the chemotactic response of neutrophils and control morphological changes in fibroblasts. The cytoskeleton is a sensor of cell volume and is essential during cell division; it may also be involved in the development of tumours (Dartsch et al., 1994; Symons, 1996). Contraction of cells involves the cytoskeleton not only for generating force within each cell, but also for transmitting contractile forces through attachment and linkage of groups of cells and interaction with tissue matrix (Hall, 1994). The diverse activities of the cytoskeleton depend on actin filaments, intermediate filaments and microtubules. Polymerized actin filaments (F-actin) elongate by stepwise addition of actin monomers to exposed ends through ATP hydrolysis (Tardif et al., 1995). However, a significant proportion of the actin is not polymerized because of the presence of actin-binding proteins (Cunningham, 1992).

Vinculin is one of several interacting focal adhesion proteins involved in anchoring $\mathrm{F}$-actin to the membrane through

*Correspondence.

Received 1 October 1997 adhesion plaques (Geiger et al., 1987). An adhesion plaque is a complex structure formed as a result of integrin heterodimers binding to extracellular matrix ligands (Pavalko and La Roche, 1993). Integrin $\beta$-subunits bind to talin which binds to vinculin, which, in turn, interacts with $\alpha$-actinin (Stromer, 1995). Since $\alpha$-actinin is known to bind to and crosslink actin filaments, vinculin represents a key element in the transmembrane linkage of the extracellular matrix to the cytoplasmic microfilament system (Stromer, 1995).

Intermediate filaments, such as cytokeratins and vimentins, are cytoplasmic structural proteins present in most vertebrate cells. Cytokeratins, a group made up of at least 29 different proteins are characteristic of epithelial cells (Moll, 1994). Vimentin is a widely distributed cytoplasmic intermediate filament protein and is present in many cells of mesodermal origin, including fibroblast, endothelial and white blood cells (van-den-Hurk et al., 1995). There is little knowledge about distribution of these proteins in myometrial smooth muscle cells.

Microtubules are structural and mobile elements involved in mitosis, intracellular transport, flagellar movement and other functions mediated by the cytoskeleton. Tubulin, the major building block of microtubules is a heterodimer $(\alpha-$ and $\beta$-subunits). Structurally different tubulin subunits are the product of different genes and the microtubular system contains at least three $\alpha$-tubulin isoforms (Burns and Surridge, 1994).

In previous studies we have investigated second messenger pathways involved in receptor activation of myometrial cells 
(Asbóth et al., 1996; Phaneuf et al., 1996; Carrasco et al., 1996). In this investigation we studied the presence of cytoskeletal elements that provide the structural support for efficient myometrial contractions. The attachment of the cells to different types of extracellular matrix protein was compared, and the close association of RhoA to F-actin was demonstrated.

\section{Materials and Methods}

\section{Materials}

Fluorescein (FITC)-conjugated phalloidin was from Molecular Probes (Eugene, OR, USA). Monoclonal mouse anti-human vinculin antibody, monoclonal mouse anti- $\alpha$-tubulin antibody, monoclonal mouse anti-cytokeratin peptide 18 antibody, monoclonal mouse anti-vimentin antibody, purified mouse immunoglobulins, sheep anti-mouse IgG FITC-conjugated antibody, EGF, fibronectin, collagens I, III and IV were obtained from Sigma Chemical Company (Poole, Dorset). Texas Red-conjugated goat anti-rabbit IgG antibody and Texas Red-conjugated goat anti-mouse IgG antibody were purchased from Jackson ImmunoResearch Laboratories (West Grove, PA). Rabbit anti-RhoA polyclonal antibody, RhoA blocking peptides and FITC-conjugated anti-rabbit IgG were obtained from Santa Cruz Biotechnology (AutogenBioclear, Calne, Wiltshire). Oxytocin was purchased from Calbiochem-Novabiochem (Nottingham). Human chorionic gonadotrophin (hCG, Profasi) was obtained from Serono Labs UK Ltd (Herts). All other reagents were commercial preparations of the highest available purity. Laminin and heparin-binding epidermal growth factor (HB-EGF) were gifts from H. Mardon (Nuffield Department of Obstetrics and Gynaecology, Oxford).

\section{Isolation and culture of myocytes}

Myometrium was obtained from six premenopausal women at hysterectomy. The operations were indicated for benign gynaecological disorders (menorrhagia, dysmenorrhoea) in patients of mixed (1-3) parity. All patients gave informed consent. Samples were taken from the middle of the uterine wall, about $5 \mathrm{~mm}$ from endometrial or serosal surfaces. Uterine leiomyomas (fibroids) were not included in this study. The tissues were collected in ice-cold Krebs solution, washed and processed for cell dispersion within $60 \mathrm{~min}$ of excision. Pieces of myometrium were incubated with gentle shaking for $2 \mathrm{~h}$ at $37^{\circ} \mathrm{C}$ in Hanks' balanced salt solution (HBSS) containing $2.5 \mathrm{mmol} \mathrm{CaCl}_{2} \mathrm{l}^{-1}, 0.9 \mathrm{mmol} \mathrm{MgCl}_{2} \mathrm{l}^{-1}$ and $10 \mathrm{mg}$ dispase $\mathrm{ml}^{-1}$. The softened pieces of tissue were then washed in $\mathrm{Ca}^{2+}$-free and $\mathrm{Mg}^{2+}$-free HBSS and cell dispersion was achieved in the same solution supplemented with collagenase (300 $\left.\mathrm{U} \mathrm{ml}^{-1}\right)$, elastase $\left(2 \mathrm{U} \mathrm{ml}^{-1}\right)$, DNAse I $\left(30 \mathrm{U} \mathrm{ml}^{-1}\right)$ and $1 \mathrm{mg} \mathrm{FAF-BSA} \mathrm{ml} \mathrm{m}^{-1}$ at $37^{\circ} \mathrm{C}$ with gentle shaking. After $2 \mathrm{~h}$, the cell suspension was aspirated with a Pasteur pipette, filtered through $250 \mu \mathrm{m}$ sterile gauze and washed three times with HBSS by centrifugation at $600 \mathrm{~g}$. The final pellet was resuspended in culture medium: Waymouth MB752/1 containing $10 \%(\mathrm{v} / \mathrm{v})$ fetal calf serum, $10000 \mathrm{iu}$ penicillin $\mathrm{ml}^{-1}$ and $10 \mathrm{mg}$ streptomycin $\mathrm{ml}^{-1}$. Viability was checked with Trypan blue and was consistently higher than $80 \%$. Myocytes were plated at densities between 0.5 and $2 \times 10^{4}$ cells $\mathrm{cm}^{-2}$ in plastic culture flasks. The myocytes were kept at $37^{\circ} \mathrm{C}$ in a humidified atmosphere of $95 \%$ air and $5 \% \mathrm{CO}_{2}$ until confluent $(6-10$ days). The medium was changed after $24 \mathrm{~h}$ and then every other day.

\section{Cell attachment}

Glass coverslips $(13 \mathrm{~mm})$ were sterilized by baking overnight and were precoated with either collagen I, collagen III, collagen IV or fibronectin, all at a concentration of $10 \mu \mathrm{g} \mathrm{ml}^{-1}$, or with laminin at $1 \mu \mathrm{g} \mathrm{ml}^{-1}$. The coverslips were then seeded with myometrial cells at $2 \times 10^{4}$ cells per well in Waymouth's medium with and without $10 \%(\mathrm{v} / \mathrm{v})$ fetal calf serum and the cells were allowed to attach for $2,6,16,24$ and $48 \mathrm{~h}$ at $37^{\circ} \mathrm{C}$ in a humidified atmosphere containing $5 \% \mathrm{CO}_{2}$.

\section{Growth factors and hormones}

Myometrial cells were incubated with EGF, HB-EGF (10-200 $\mathrm{ng} \mathrm{ml}^{-1}$ ) or hCG $\left(0.1-1.0 \mathrm{iu} \mathrm{ml}^{-1}\right)$, for $1 \mathrm{~h}, 6 \mathrm{~h}$ and $16 \mathrm{~h}$ before fixing and staining for cytoskeletal proteins. In separate experiments, the cells were challenged with oxytocin $\left(1 \mu \mathrm{mol} \mathrm{l}{ }^{-1}\right)$ for $45 \mathrm{~s}, 5 \mathrm{~min}$ and $3 \mathrm{~h}$ before fixing and staining.

\section{Immunohistochemistry}

At the times indicated the coverslips were washed twice with warm $\left(37^{\circ} \mathrm{C}\right)$ phosphate-buffered saline (PBS). The cells were then fixed in $3 \%(\mathrm{w} / \mathrm{v})$ paraformaldehyde diluted in PBS at room temperature for $5 \mathrm{~min}$, followed by incubation in permea-

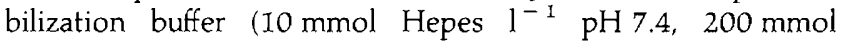
sucrose $1^{-1}, 3 \mathrm{mmol} \mathrm{MgCl}_{2} \mathrm{l}^{-1}, 50 \mathrm{mmol} \mathrm{NaCl} \mathrm{l}^{-1}, 0.5 \%$ $(\mathrm{v} / \mathrm{v})$ Triton $\mathrm{X}-100,0.2 \%(\mathrm{w} / \mathrm{v})$ sodium azide) for $5 \mathrm{~min}$. Finally, the coverslips were washed twice in PBS containing 3\% (w/v) $\mathrm{BSA}$ and the cells were exposed to the appropriate conjugates or antibodies for 45-60 min in the dark at room temperature. After staining, the coverslips were mounted on glass slides with polyvinyl alcohol ready for analysis under the fluorescence microscope.

Actin. Polymerized F-actin was visualized with FITCconjugated phalloidin (dilution 1:40), based on the ability of phalloidin to bind actin (Allen et al., 1996).

Vinculin. Vinculin was stained with a monoclonal antibody to human vinculin (dilution 1:400), derived from mouse ascites fluid. The coverslips were washed in PBS/0.05\% (w/v) BSA for $5 \mathrm{~min}$ and visualized with Texas-Red conjugated goat-anti-mouse IgG antibody.

Cytokeratin. A monoclonal FITC-conjugated mouse anti-cytokeratin peptide 18 antibody was used in the presence of $2 \%$ normal human serum at $\mathrm{I}$ in 100 dilution. 
Vimentin. The cells were incubated with the primary antibody to vimentin (dilution 1:40), washed in PBS and then incubated with sheep anti-mouse IgG FITC-conjugate.

Tubulin. The cells were incubated with a monoclonal antibody against $\alpha$-tubulin (dilution 1:2000), washed in PBS and then incubated with sheep anti-mouse IgG FITC-conjugate.

RhoA. The cells were incubated with primary antibody against RhoA (dilution 1:100), washed in PBS and then incubated in Texas-red conjugated goat anti-rabbit IgG antibody.

Negative controls. These were carried out by omitting the primary antibodies and by blocking with purified mouse immunoglobulins. Furthermore, RhoA antibodies were preabsorbed with cognate peptides.

Image analysis. Cells were visualized with a Leica DMRBE epifluorescence microscope and images were captured using the Biovision software package (Improvision, Warwick Science Park, Coventry) on an Apple Macintosh computer. Images were captured in standard formats and the cells were counted and measured using calibrated image estimations. Red and green fluorescent images were taken from the same fields using appropriate light frequencies and filters.

\section{Statistical analyses}

Experiments were carried out using four coverslips for each condition and were repeated at least twice using different cell cultures. The effect of the various extracellular matrices or hormones on cytoskeletal structures was assessed in a minimum of 100 cells per different time or condition. Quantitative differences were assessed by Student's $t$ test.

\section{Results}

\section{Effect of extracellular matrix on cell attachment}

The attachment of cells was studied comparing several matrices (collagen I, collagen III, collagen IV, fibronectin and laminin), with and without serum in the medium. Under all conditions, cell attachment was very poor for at least $6 \mathrm{~h}$. However, after incubation for $16 \mathrm{~h}$ there were clear differences. Cells incubated in the presence of serum attached much better than in serum-free medium and tended to align themselves in parallel, reminiscent of myometrial smooth muscle cell bundles in fresh tissue (Fig. 1). Collagen IV and, to a lesser extent, fibronectin, improved cell attachment in serum-free conditions whereas collagens I and III and laminin had no significant effect. In the presence of serum, collagen IV and fibronectin accelerated the rate of ceil attachment, although after $24-48 \mathrm{~h}$ there was excellent attachment irrespective of the matrix used, probably because in serum-rich conditions myometrial cells were able to synthesize or deposit enough matrix proteins. For further experiments, myometrial cells were routinely allowed to attach for $24 \mathrm{~h}$ on a matrix of collagen IV.

\section{Distribution of actin, vinculin and RhoA}

Myometrial cells were very rich in actin stress fibres which were generally oriented along the longest axis of the cells (Fig. 2). Actin fibres often spanned the whole length of the cell. There was a strong expression of vinculin (Fig. 3) which concentrated at adhesion plaques. It was possible, using a double staining technique, to demonstrate the colocalization of vinculin and the termini of actin fibres in focal adhesion plaques (Fig. 4).

By contrast, RhoA had a diffuse, granular distribution and tended to accumulate in the centre of the cell. Nevertheless there was also an intimate association between RhoA protein and actin fibres (Fig. 5). Thus, vinculin-actin focal adhesion complexes provide the basis for myometrial cell attachment to the extracellular matrix and for the architectural integrity of the cells, whereas RhoA may be a link between hormonal and other signals reaching myometrial cells and the regulation of actin dynamics.

\section{Intermediate filaments}

The intermediate filaments cytokeratin and vimentin revealed a complex and dense mesh of cytoskeletal structures which occupied the cytoplasmic compartment but excluded the nucleus, providing a clear 'negative' impression of the nuclear space. There was stronger staining for vimentin than for cytokeratin, but both components of the intermediate cytoskeleton followed a similar pattern (Figs 6 and 7). The presence of cytokeratin was somewhat surprising as this protein is usually found in cells of epithelial origin (O'Keane et al., 1992).

\section{Microtubules}

Myometrial cells had a dense basketwork of microtubules as revealed with the tubulin antibody. Microtubules were seen in greatest density around the nucleus where they radiated out into the cell periphery in fine lacelike threads. This tubular arrangement is essential for the transport of vesicles and organization of cytoplasmic organelles in the cells. Again, the nuclear space was clearly delineated (Fig. 8).

\section{Effect of growth factors and hormones}

When myometrial cells were incubated in the presence of EGF, we observed an increase of cytoplasmic extensions resembling filopodia, more evident at the leading edge of the cells, but also in areas of cell to cell contact; otherwise the morphology of the cells was very similar to serum control. The effect of EGF was evident only when the cells were treated with $200 \mathrm{ng} 1^{-1}$ for $16 \mathrm{~h}$ (Fig. 9). HB-EGF at the same dose had little effect. Exposure of the cells to 1 iu $h C G \mathrm{l}^{-1}$ for $16 \mathrm{~h}$ provoked a small increase in filopodia; otherwise there was no apparent effect on cell morphology.

Oxytocin provoked a rapid but transient effect on actin organization, which resulted in apparent shortening of the cytoskeleton. For quantitating the effect of oxytocin, the length of the actin cytoskeleton of individual cells was measured along their longest axis. The results showed that oxytocin provoked 

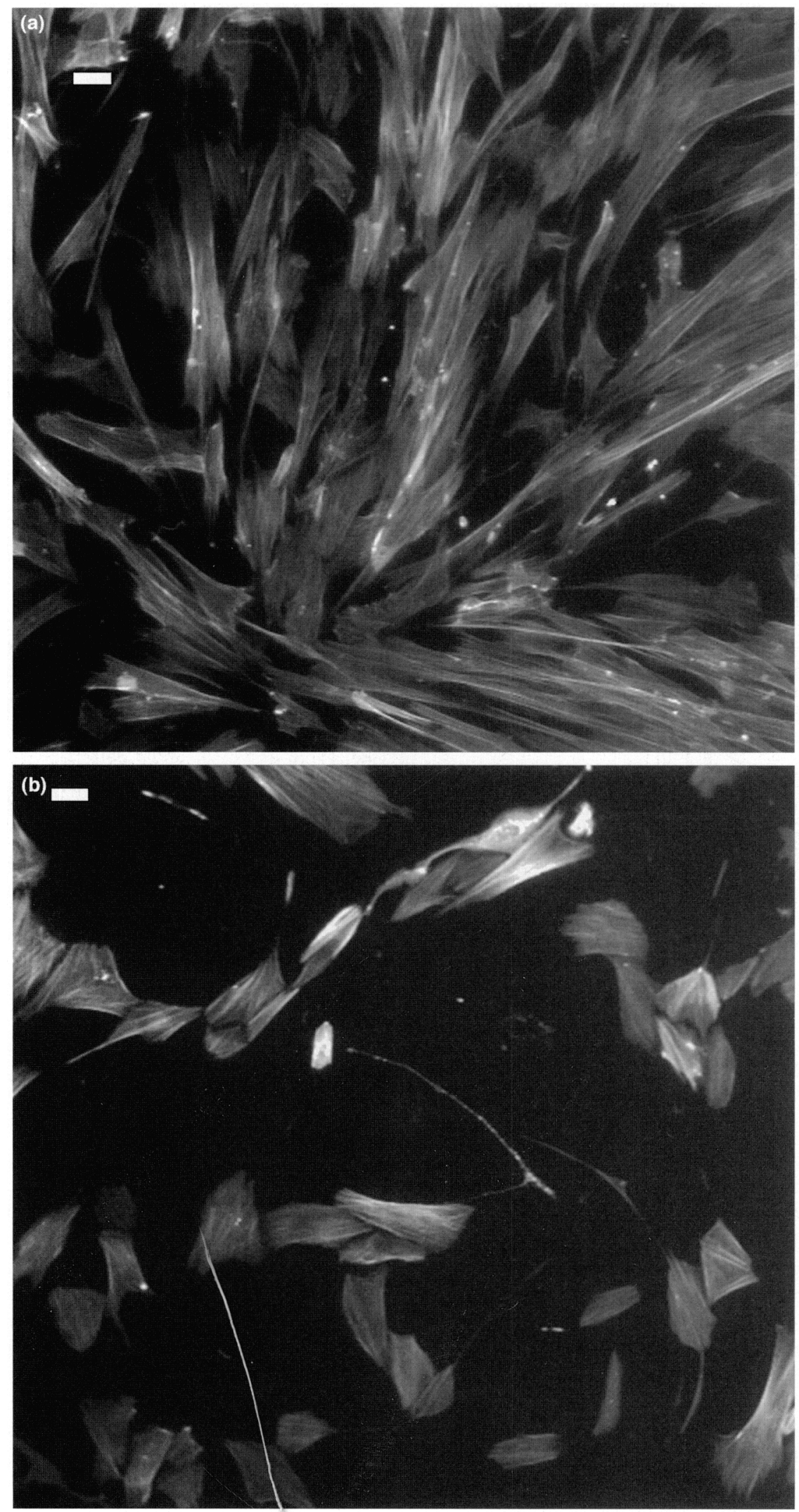

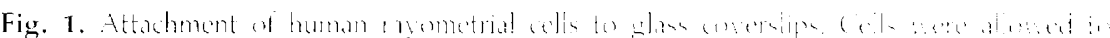

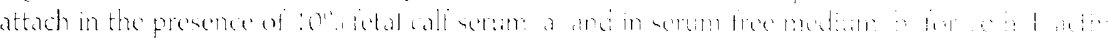

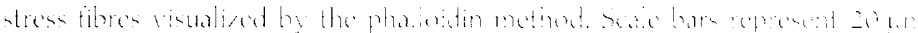




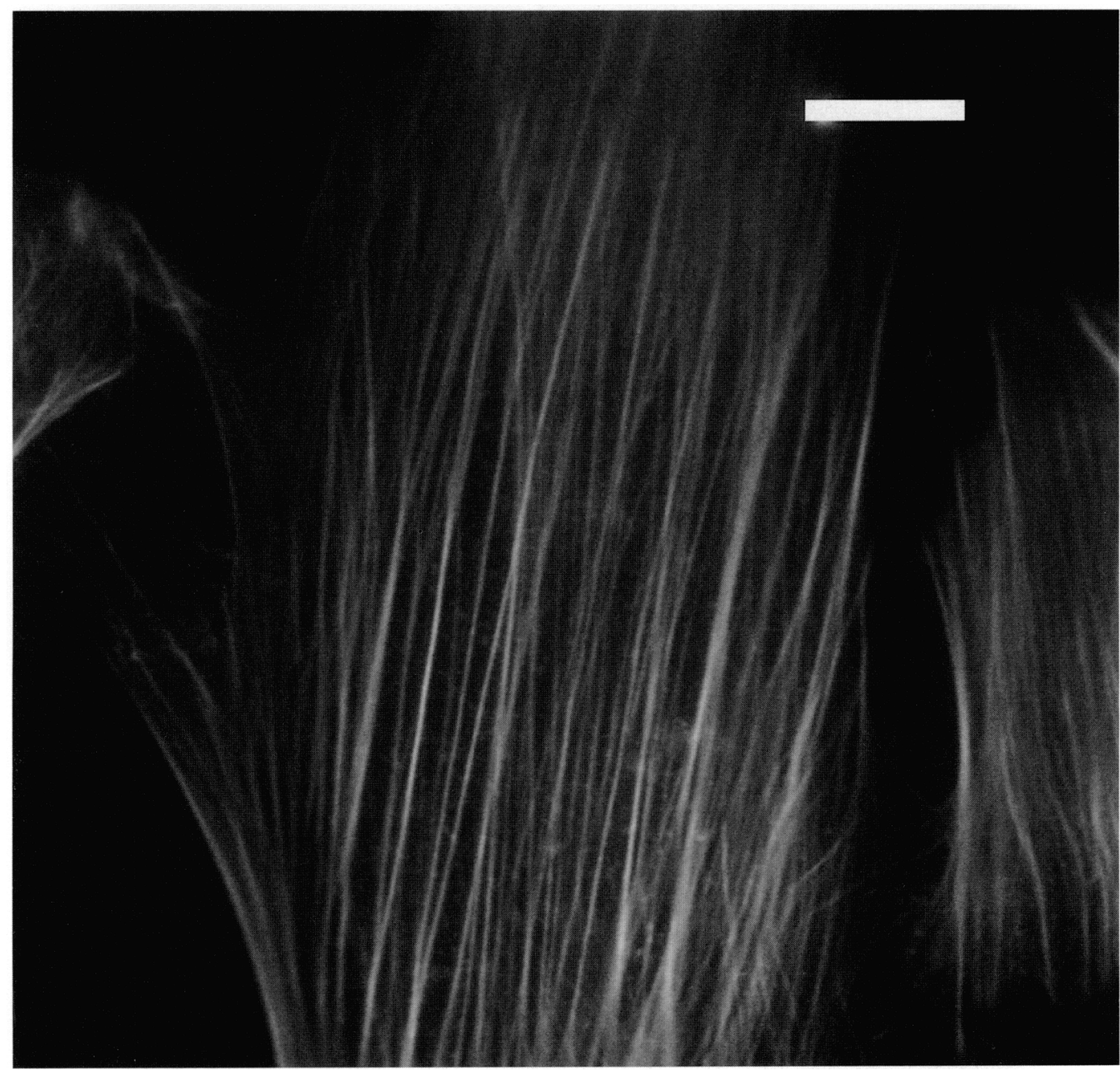

Fig. 2. Actin stress fibres in human myometrial cells. Note the abundance of filaments in a predominately longitudinal orientation. The cells were allowed to atłach in $10 \%$ serum for $24 \mathrm{~h}$. Scale bar represents $20 \mu \mathrm{m}$.

a significant shortening of the actin fibres after $45 \mathrm{~s}$ and $5 \mathrm{~min}$ of exposure, but the effect was not seen after $3 \mathrm{~h}$ (Table 1 ).

\section{Discussion}

This is the first comprehensive demonstration of cytoskeletal proteins in human myometrial cells. In the uterus, myometrial smooth muscle cells are arranged in bundles that are embedded in a matrix of connective tissue consisting mainly of collagen. The human uterus has collagens types I, III, IV, V and VI (Karkavelas et al., 1988) which form a dense matrix that facilitates the transmission of the contractile forces generated by the individual myometrial cells. We compared several matrix components and found that, under our in vitro conditions, collagen IV resulted in accelerated cell attachment. Type IV collagen molecules have a more flexible structure than the fibrillar collagens. Their triple-stranded helix is interrupted in 26 regions, allowing multiple bends (Eyre et al., 1984). Electron microscope studies of preparations of assembling type IV collagen molecules suggest that these molecules associate by their carboxyl termini to form head-to-head dimers, which then form an extended lattice via amino-terminal associations with three other collagen molecules (Eyre et al, 1984). Disulphide and other covalent cross-links between the collagen molecules stabilize these associations. The resulting meshwork forms an insoluble scaffolding to which other components of the basal lamina bind via their specific associations with type IV collagen molecules (Shimizu et al., 1997). The ability of type IV collagen to assemble into a multilayer meshwork might provide better attachment of myometrial cells onto the coverslips. The cells had a tendency to align themselves in bundle-like structures resembling their distribution in fresh myometrium (Scoutt et al., 1991).

The cytoskeleton is a structure primarily involved in linking or connecting protein filaments to each other and to anchoring sites in the adhesion plaques (Gilmore and Burridge, 1996). Our data demonstrate a complex array of cytoskeletal structures in myometrial cells. There was a high density of parallel actin fibres usually in the direction of the longest axis, and their presence is in good agreement with the contractile function of these cells. The actin filaments provide strong cytoskeletal 


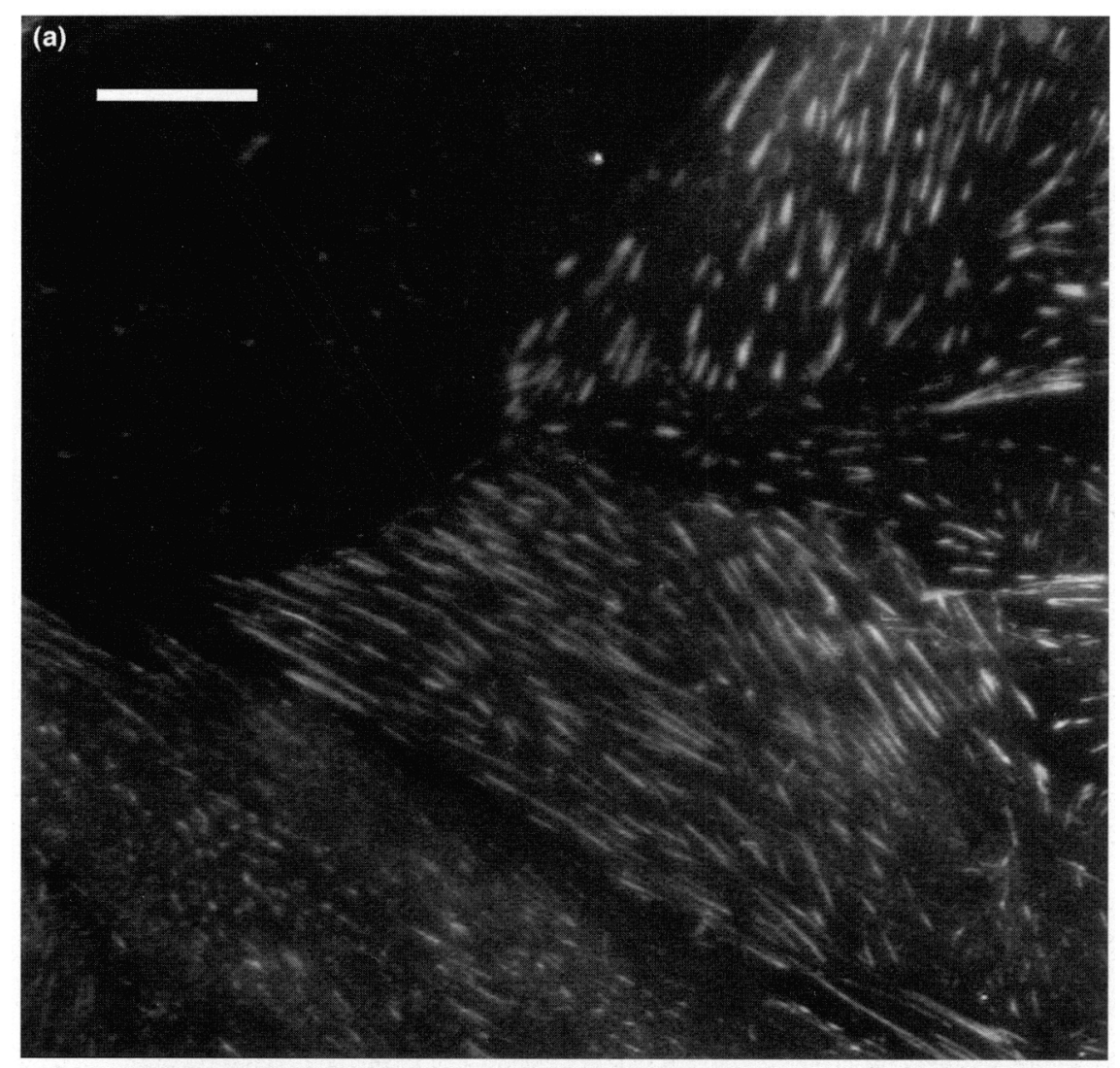

(b)

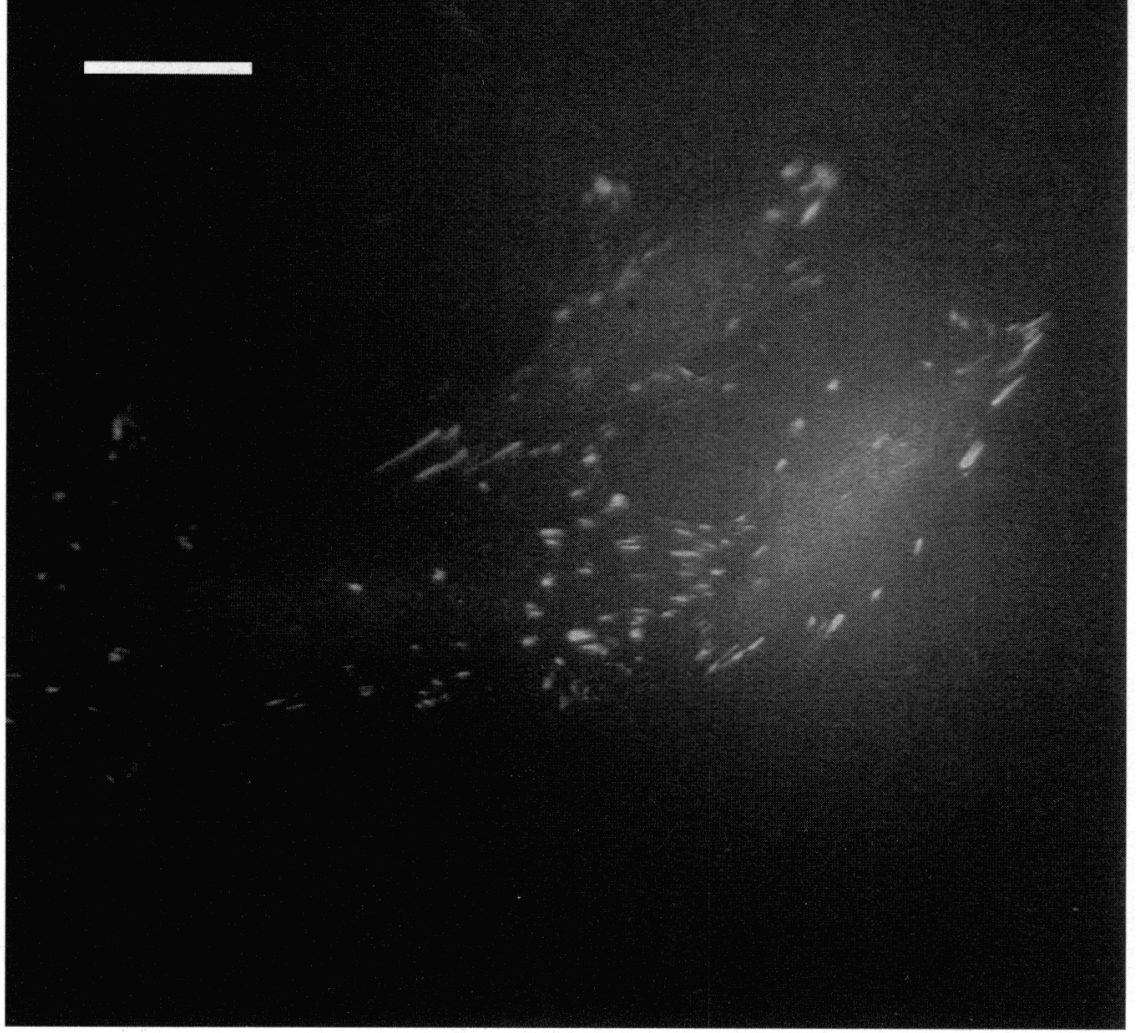

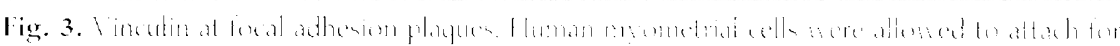

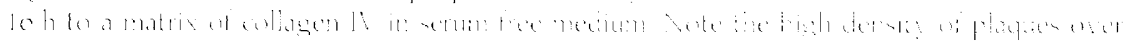

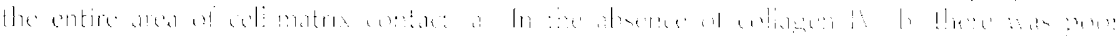

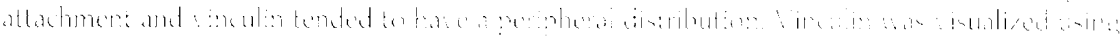


reprent 21 : 

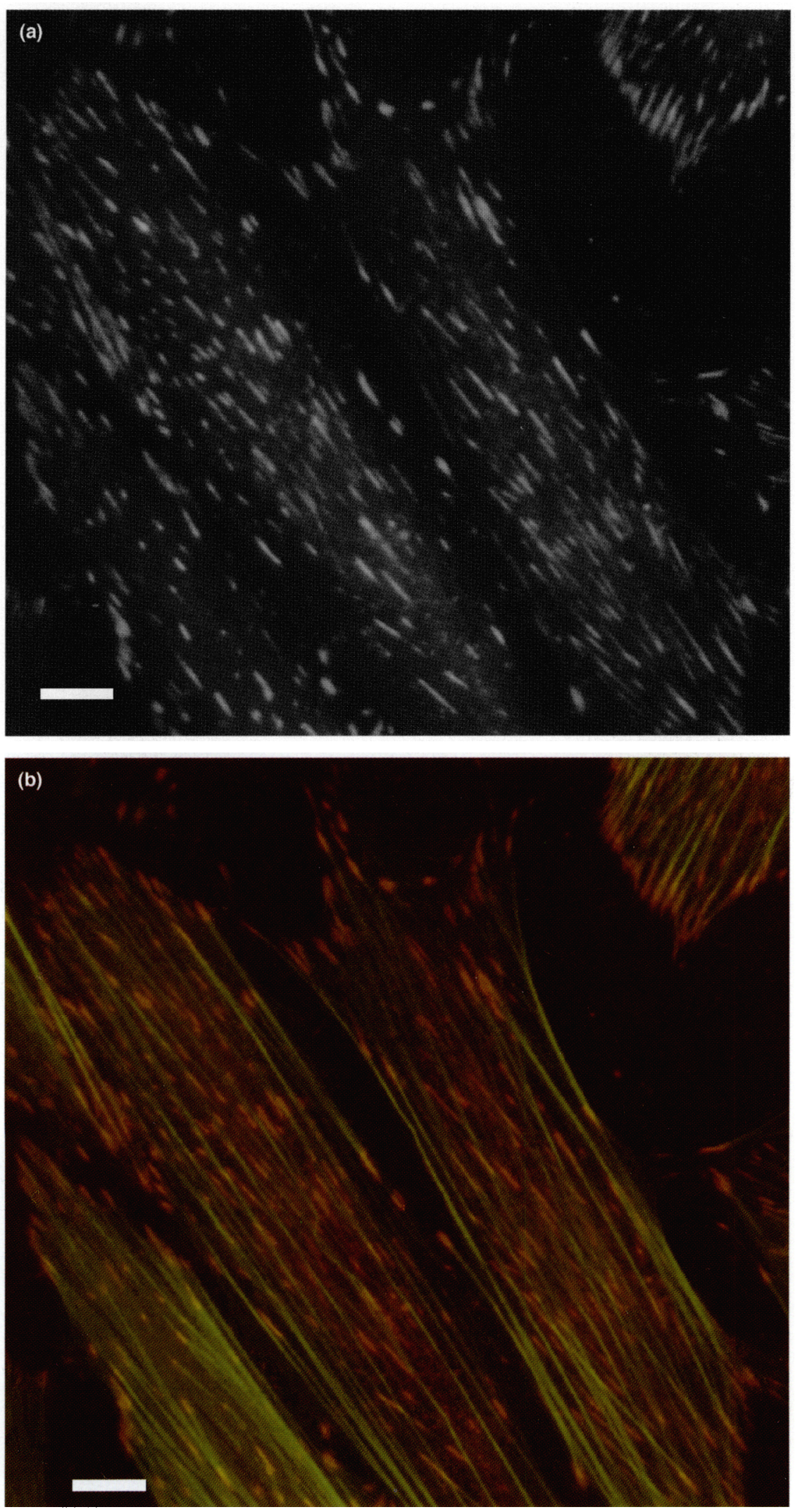

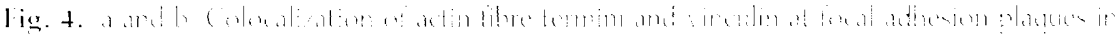

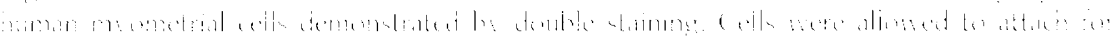

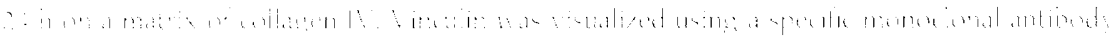

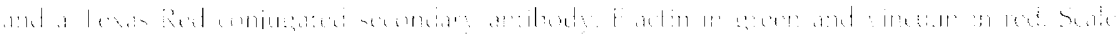
$\therefore \cdots+1, \cdots+\cdots$ 




(b)

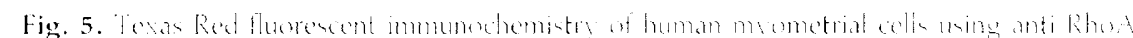

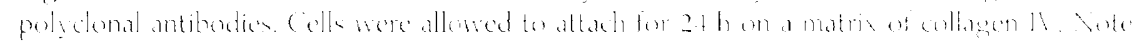



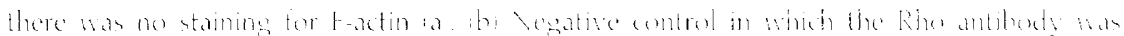

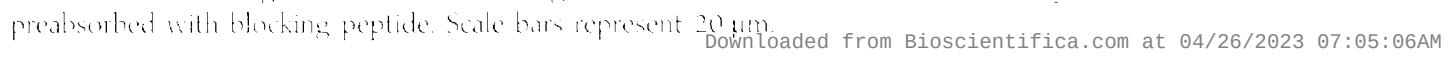




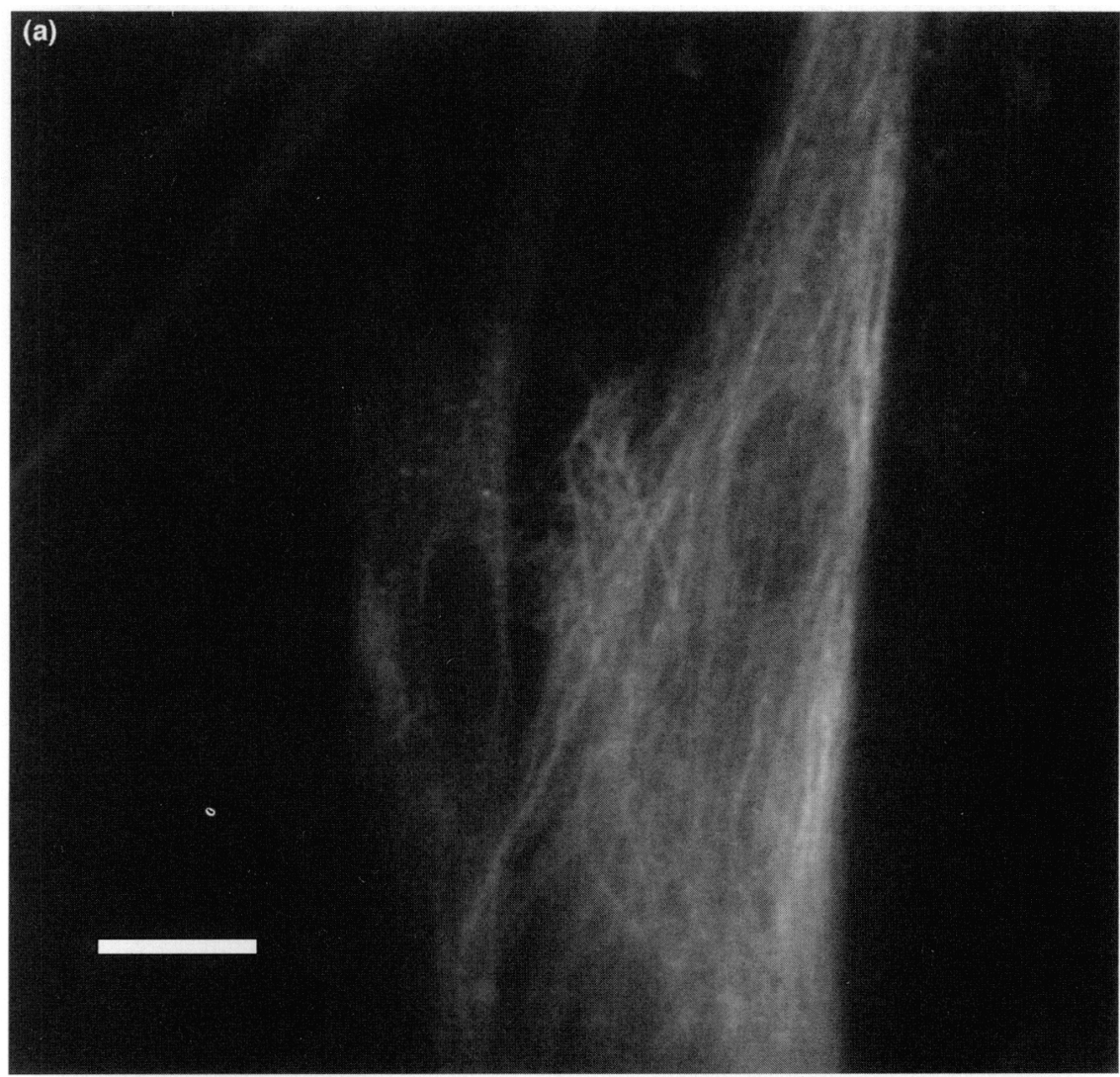

(b)

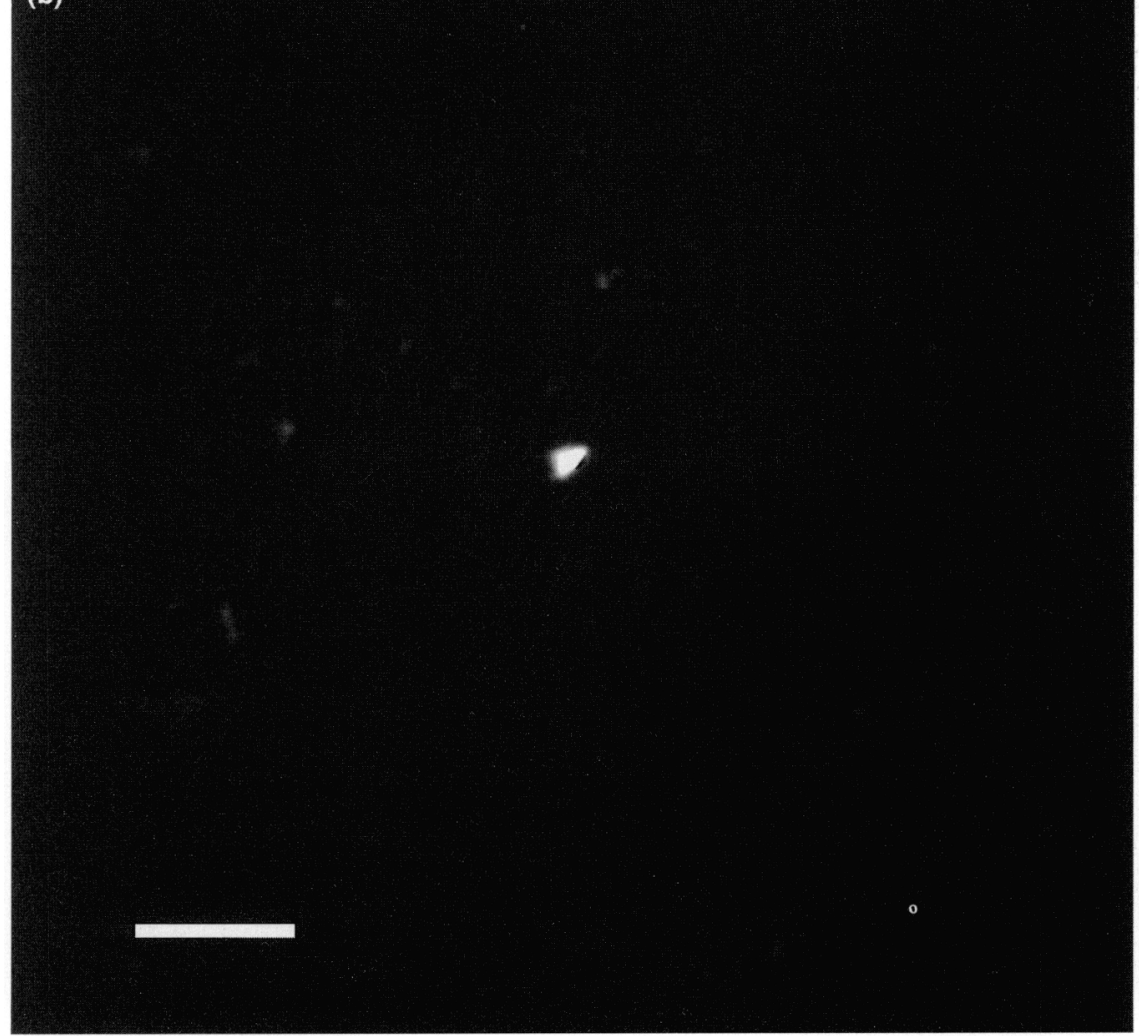

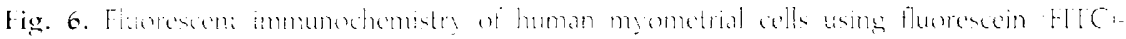

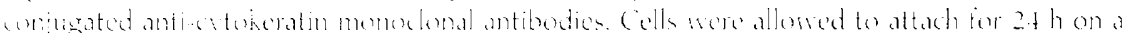

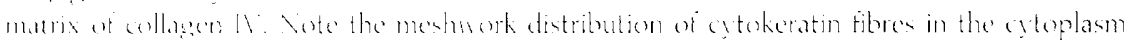

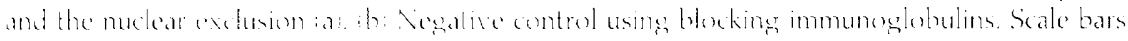






(b)
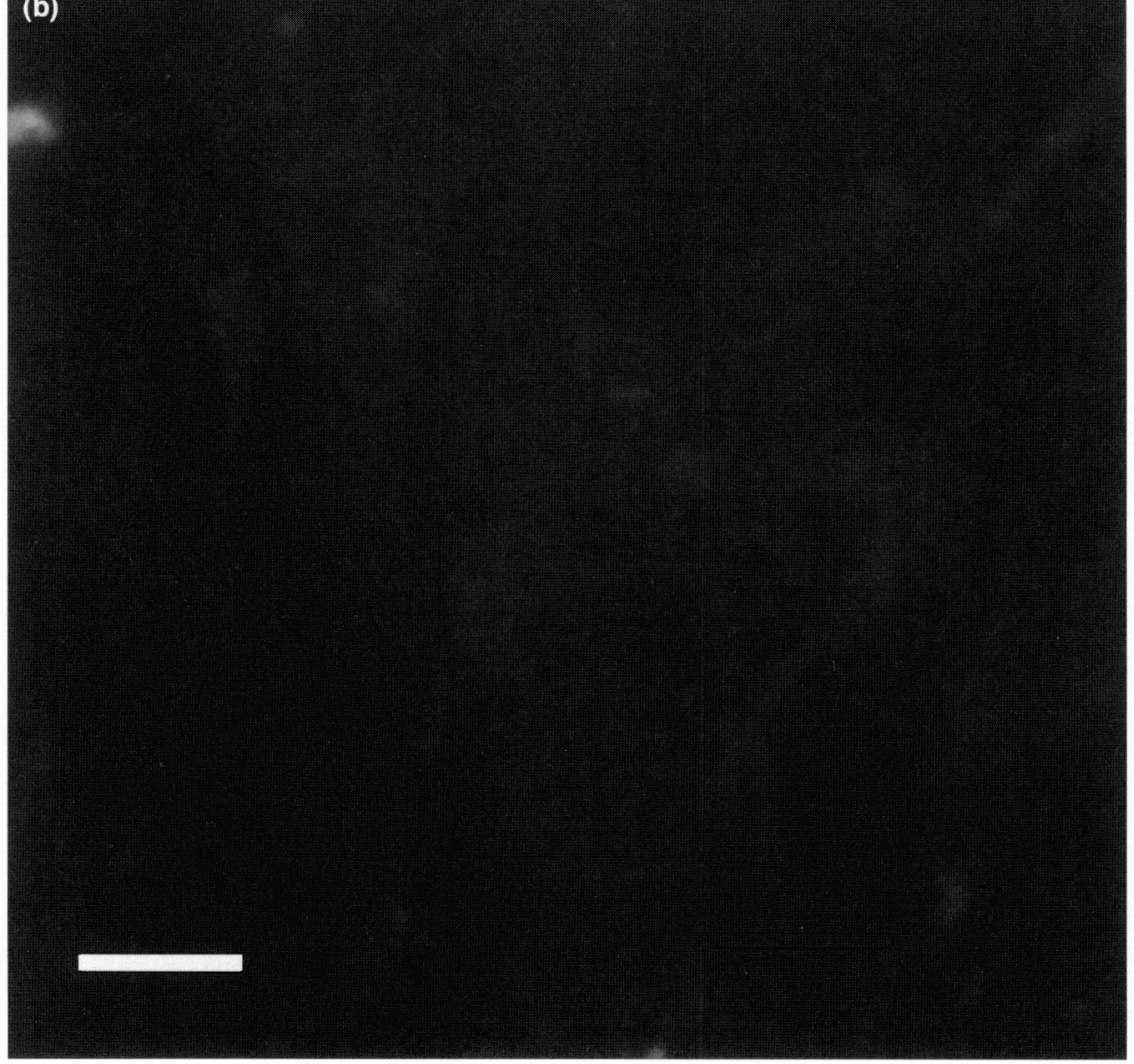

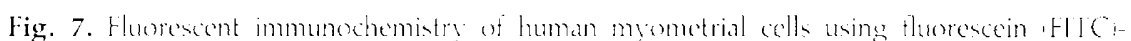

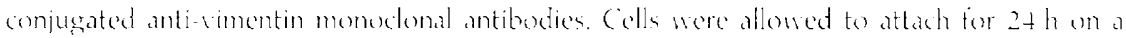
matrix of collagen IV. Vole the dense hair like structure within the cytoplasm ias ib Xegative control without the primary anti-eimentin antibody. Sale bars represent 20 . 



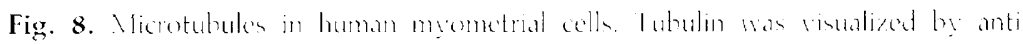

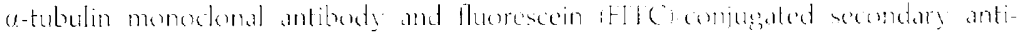





bridges between focal adhesion points and we were able to show by double immunostaining an intimate selationship between vinculin, a major component protein of focal adthe-

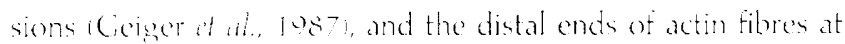
the coll membrane. (Obliquely organized contractile filaments bedonging to a longitudinal cytoskeletal framework and a 



Fig. 9. Effect of (a) epidermal growth factor (EGF), (b) heparin-binding EGF and (c) hCG on cultured human myometrial cells; (d) control. The cells were allowed to attach to a matrix of collagen IV in the presence of serum for $24 \mathrm{~h}$. After attachment they were washed and exposcd to growth factors and hormones. The arrows point to actin-rich filopodia-like extensions. Scale bar represents 20 um.

multitude of vinculin attachments allow the cells to exert tension on the surrounding extracellular matrix over their entire length. Actin-associated membrane complexes are essential for co-ordinated cell motility in fibroblasts and other cell types (Cunningham, 1992), and it is likely that actin/vinculin attachments to the collagen matrix via integrins are required for effective uterine smooth muscle activity. Morcover, actin-associated proteins are known to interact with the contractile machinery and may be actively involved in the maintenance of tension. For example, calponin has been implicated in the regulation of smooth muscle contraction through its interaction with F-actin and inhibition of the actin-activated $\mathrm{Mg}^{2-}$-ATPase activity of phosphorylated myosin (Borovikov ef al., 1996).

Contractions in myometrial cells are known to be activated primarily by the activation of $\mathrm{Ca}^{2+} / \mathrm{calmodulin-dependent}$ myosin light chain kinase (Word of nl., 1994). Oxytocin stimulates myometrial contractility by increasing intracellular calcium. This involves coupling of the oxytocin receptor to phospholipase C- $\beta$ by CTP-binding proteins ( $G$ proteins) of the $\mathrm{Gq}$ and Gi families (Phaneuf et al., 1993; Ku it al., 1995; Phaneuf of al, 1990). Moreover, oxytocin can activate small G proteins of the Rho family and preliminary data suggest that oxytocin provokes translocation of RhoA to the cytoskeletal 
Table 1. Effect of oxytocin on the maximum length $(\mu \mathrm{m})$ of polymerized actin fibres in human myometrial cells

\begin{tabular}{|c|c|c|c|c|}
\hline & Basal & $45 \mathrm{~s}$ & $5 \min$ & $3 \mathrm{~h}$ \\
\hline Experiment 1 & $92.8 \pm 27.3$ & $84.8 \pm 27.1^{*}$ & $84.4 \pm 21.6^{*}$ & N.D. \\
\hline Experiment 2 & $94.5 \pm 24.8$ & $83.3 \pm 26.7^{*}$ & $82.8 \pm 22.9 *$ & $93.8 \pm 25.7$ \\
\hline
\end{tabular}

\footnotetext{
The cells were challenged with $1 \mu \mathrm{mol}$ oxytocin $1^{-1}$ for the times indicated.

$* P<0.01$ compared with control cells; means $\pm S D ; n=100-105$ for each.

ND: not determined.
}

compartment in rat myometrium (Ruzycky, 1997a). RhoA is thought to link cell membrane receptors to the organization of actin into stress fibres and the phosphorylation of thick filament components (Ridley, 1996). Double immunostaining of actin and RhoA showed a strong association between the two. In human myometrial cells RhoA is thought to enhance the calcium sensitivity of smooth muscle contractions (Ruzycky, 1997b). There are several mechanisms by which Rho can enhance myosin activation; for instance, Rho inhibits myosin phosphatase favouring myosin phosphorylation indirectly (Kimura et al., 1996) and it can also promote direct myosin light chain phosphorylation via stimulation of Rho kinase (Amano et al., 1996). Recent data have demonstrated a direct contractile effect of Rho kinase in vascular smooth muscle through myosin light chain phosphorylation (Kureishi et al., 1997); whether a similar system operates in myometrium requires investigation. It is possible that oxytocin initiates myometrial activation through the $G$ protein calcium pathway, with further potentiation of contractions involving a RhoA-mediated increase in actin polymerization (Ruzycky, 1997a).

Myometrial cells show a marked increased in protein phosphorylation in response to EGF (Carrasco et al., 1996) which operates through the intrinsic tyrosine kinase activity of its receptor (Wahl et al., 1989). EGF has mitogenic effects and may be involved in uterine growth in pregnancy and in fibroid formation (Harrison-Woolrych et al., 1994). Furthermore myometrial EGF receptors increase during spontaneous labour (Gargiulo et al, 1997) and it is thought that EGF may favour parturition by increasing prostaglandin production by intrauterine cells (Pollard and Mitcheil, 1996). Our data suggest that EGF increases the presence of actin-associated cytoplasmic projections, reminiscent of filopodia and other structures which appear at points of neuronal cell growth (O'Connor and Bentley, 1993) and during movement in fibroblasts (Small, 1994). The function of filopodia in myometrial cells is not clear, but they may serve to increase cell to cell contact to provide a synchronized response to hormonal and electrical stimuli during uterine activation.

Intermediate filaments (cytokeratin and vimentin) were very dense and prominent in myometrial cells which was somewhat unexpected as such complexity is usually ascribed to cells of neuronal and epithelial origin (Stagaard and Mollgard, 1989). Moreover, there was strong cytoplasmic staining for tubulin. It is now accepted that apart from their specialized contractile function, myometrial cells have secretory properties, for example they release interstitial collagenase (Jeffrey et al., 1991). Microtubules are long stiff polymers found throughout the cytosol which govern the location of membrane-bound organelles and other cell components. Microtubule formation is essential during mitosis, and although in this study we have not investigated cell division, the strong presence of tubulin may be related to the enormous capacity of myometrial cells for hypertrophy and hyperplasia during pregnancy.

In summary, we have demonstrated a complex cytoskeletal structure in human myometrial cells. Although there are many studies on myometrial function at the level of receptor/second messenger activation and electrophysiological mechanisms, the role of the cytoskeleton has received little attention. Our findings emphasize the need to address the interaction of cytoskeletal proteins with extracellular matrix components and the response of these proteins to signalling events during myometrial activation, in order to achieve a full understanding of the mechanism of contractility.

The authors are grateful to $H$. Mardon for help and advice, to R. Grant for technical help on the use of Biovision equipment and to G. Asbóth and J. Bellinger for help with myometrial cell culture.

\section{References}

Allen PG, Shuster CB, Kas J, Chaponnier C, Janmey PA and Herman IM (1996) Phalloidin binding and rheological difference among actin isoforms Biochemistry $35 \quad 14062-14069$

Amano M, lto M, Kimura K, Fukata $Y$, Chihara K, Nakano T, Matsuura $Y$ and Kaibuchi K (1996) Phosphorylation and activation of myosin by Rho-associated kinase (Rho-kinase) Journal of Biological Chemistry 271 $20246-20249$

Asbóth G, Phaneuf S, Europe-Finner GN, Toth M and López Bernal A (1996) Prostaglandin $E_{2}$ activates phospholipase $C$ and elevates intracellular calcium in cultured myometrial cells: involvement of EP1 and EP3 receptor subtypes Endocrinology $1372572-2570$

Borovikov YuS, Horiuchi KY, Avrova SV and Chacko S (1996) Modulation of actin conformation and inhibition of actin filament velocity by calponin Biochemistry $3513849-13857$

Burns RG and Surridge CD (1994) Functional role of a consensus peptide which is common to alpha-, beta- and gamma-tubulin, to actin and centractin, to phytochrome $\mathrm{A}$, and to the TCP1 alpha chaperonin protein FEBS Letters 347 105-111

Carrasco MP, Phaneuf S, Asboth G and López Bernal A (1996) Fluprostenol activates phospholipase $\mathrm{C}$ and $\mathrm{Ca}^{2+}$ mobilization in human myometrial cells Journal of Clinical Endocrinology and Metabolism 81 2104-2110

Cunningham CC (1992) Actin structural proteins in cell motility Cancer and Metastasis Reviews 11 69-77

Dartsch PC, Ritter M, Haussinger D and Lang F (1994) Cytoskeletal reorganisation in NIH 3 T3 fibroblasts expressing the ras oncogene European Journal of Cell Biology 63 316-325

Eyre DR, Paz MA and Gallop PM (1984) Cross-linking in collagen and elastin Annual Reviews in Biochemistry 53 717-748 
Gargiulo AR, Khan-Dawood FS and Dawood MY (1997) Epidermal growth factor receptors in uteroplacental tissues in term pregnancy before and after the onset of labour Journal of Clinical Endocrinology and Metabolism 82 $113-117$

Geiger B, Volk T, Volberg T and Bendori R (1987) Molecular interactions in adherens-type contacts Journal of Cell Science (Supplement) 8 251-272

Gilmore AP and Burridge K (1996) Regulation of vinculin binding to talin and actin by phosphatidyl-inositol-4-5-bisphophate Nature 381 531-535

Hall A (1994) Small GTP-binding proteins and the regulation of the actin cytoskeleton Annual Reviews in Cell Biology 10 31-54

Harrison-Woolrych ML, Charnock-Jones DS and Smith SK (1994) Quantification of messenger ribonucleic acid for epidermal growth factor in human myometrium and leiomyomata using reverse transcriptase polymerase chain reaction Journal of Endocrinology and Metabolism 78 1179-1184

Jeffrey JJ, Ehlich LS and Roswit WT (1991) Serotonin: an inducer of collagenase in myometrial smooth muscle cells Journal of Cell Physiology 146 399-406

Karkavelas G, Kefalides NA, Amenta PS and Martinez-Hernandez A (1988) Comparative ultrastructural localization of collagen types III, IV, VI and laminin in rat uterus and kidney Journal of Ultrastructure and Molecular Structural Research 100 137-155

Kimura K, Ito M, Amano M, Chihara K, Fukata Y, Nakafuku M, Yamamori B, Feng J, Nakano T, Okawa K, Iwamatsu A and Kaibuchi K (1996) Regulation of myosin phosphatase by Rho and Rho-associated kinase (Rho-kinase) Science $273245-248$

Ku CY, Qian A, Wen Y, Anwer K and Sanborn BM (1995) Oxytocin stimulates myometrial guanosine triphosphatase and phospholipase- $\mathrm{C}$ activities via coupling to $\mathrm{G} \alpha_{9 / 11}$ Endocrinology 136 1509-1515

Kureishi Y, Kobayashi S, Amano M, Kimura K, Kanaide H, Nakano T, Kaibuchi K and Ito M (1997) Rho-associated kinase directly induces smooth muscle contraction through myosin light chain phosphorylation Journal of Biological Chemistry 272 12 257-12 260

Moll R (1994) Cytokeratins in the histological diagnosis of malignant tumors International journal of Biological Markers 9 63-69

Murphy C, Saffrich R, Grummt M, Gournier H, Rybin V, Rubino M, Auvinen P, Lutcke A and Parton RG (1996) Endosome dynamics regulated by a Rho protein Nature $384427-432$

O'Connor TP and Bentley D (1993) Accumulation of actin in subsets of pioneer growth cone filopodia in response to neural and epithelial guidance cues in situ. Journal of Cell Biology 123 935-948

O'Keane JC, Stahl D, Sheahan K, Burke B, Gottlieb LS and O'Brien MJ (1992) Analysis of epithelial and lymphoid phenotypic markers in relation to growth pattern of colorectal adenomas Human Pathology 23 1038-1043

Pavalko FM and La Roche SM (1993) Activation of human neutrophils induces and interaction between the integrin beta 2-subunit (CD18) and the actin binding protein alpha-actinin Journal of Immunology 151 3795-3807

Phaneuf S, Europe-Finner GN, Varney M, MacKenzie IZ, Watson SP and López Bernal A (1993) Oxytocin-stimulated phosphoinositide hydrolysis in human myometrial cells: involvement of pertussis toxin-sensitive and -insentitive G-proteins Journal of Endocrinology 136 497-509

Phaneuf S, Carrasco MP, Europe-Finner GN, Hamilton CH and López Bernal A (1996) Multiple G proteins and phospholipase $C$ isoforms in human myometrial cells: implication for oxytocin action Journal of Clinical Endocrinology and Metabolism 81 2098-2103

Pollard JK and Mitchell (1996) Effects of gestational age on prostaglandin production and its regulation in human myometrial cells Journal of Maternal Fetal Medicine 5 93-98

Ridley AJ (1996) Rho theme and variations Current Biology 6 1256-1264.

Ruzycky AL (1997a) Agonist-specific changes in actin filament polymerisation are associated with increased cytoskeletal signalling in the rat myometrium Journal of the Society of Gynaecological Investigation 4 (Supplement) 106A

Ruzycky AL (1997b) Pregnancy increases the expression of cytoskeletal signalling GTPases, rac-I and RhoA, in human uterine myocytes Journal of the Society of Gynaecological Investigation 4 (Supplement) 162A

Scoutt LM, Flynn SD, Luthringer DJ, McCauley TR and McCarthy SM (1991) Junctional zone of the uterus: correlation of MR imaging and histologic examination of hysterectomy specimens Radiology 179 403-407

Shimizu M, Minakuchi K, Moon M and Koga J (1997) Difference in interaction of fibronectin with type I collagen and type IV collagen Biochimica et Biophysica Acta 1339 53-61

Small JV (1994) Lamellipodia architecture: actin filament turnover and the lateral flow of actin filaments during motility Seminars in Cell Biology $\mathbf{5}$ $157-163$

Stagaard M and Mollgard K (1989) The developing neuroepithelium in human embryonic and fetal brain studied with vimentin-immunocytochemistry Anatomy and Embryology 180 17-28

Stromer MH (1995) Immunocytochemistry of the muscle cell cytoskeleton Microscopy Research Technigues 31 95-105

Symons M (1996) Rho family GTPases: the cytoskeleton and beyond Trends in Biochemical Sciences 21 178-181

Tardif M, Huang S, Redmond T, Safer D, Pring M and Zigmond SH (1995) Actin polymerization induced by GTP gamma $S$ in permeabilized neutrophils is induced and maintained by free barbed ends Journal of Biological Chemistry $27028075-28083$

Van-den-Hurk R, Dijkstra G, van-Mil FN, Hulshof SC and van-den-Ingh TS (1995) Distribution of the intermediate filament proteins vimentin, keratin, and desmin in the bovine ovary Molecular Reproduction and Development 41 459-467

Wahl MI, Nishibe S, Suh PG, Rhee SG and Carpenter G (1989) Epidermal growth factor stimulates tyrosine phosphorylation of phospholipase C-II independently of receptor internalization and extracellular calcium Proceedings of National Academy of Sciences USA 86 1568-1572

Word RA, Tang D-C and Kamm KE (1994) Activation properties of myosin light chain kinase during contraction/relaxation cycles of tonic and phasic smooth muscles Journat of Biological Chemistry 26921 596-21 602 